Article

\title{
New Insights on the Role of Allyl Isothiocyanate in Controlling the Root Knot Nematode Meloidogyne hapla
}

\author{
Paul Dahlin $1, *$ (D) and Johannes Hallmann ${ }^{2, *(\mathbb{D})}$ \\ 1 Agroscope, Research Division, Plant Protection, Phytopathology and Zoology in Fruit and Vegetable \\ Production, 8820 Wädenswil, Switzerland \\ 2 Julius Kühn Institute, Federal Research Centre for Cultivated Plants, Institute for Epidemiology and \\ Pathogen Diagnostics, 38104 Braunschweig, Germany \\ * Correspondence: paul.dahlin@agroscope.admin.ch (P.D.); johannes.hallmann@julius-kuehn.de (J.H.); \\ Tel.: +41-58-480-84-87 (P.D.)
}

Received: 31 March 2020; Accepted: 5 May 2020; Published: 9 May 2020

check for updates

\begin{abstract}
Biofumigation, although a well-known method, is still controversially debated as a management strategy for plant-parasitic nematodes (PPN). Its controlling effect is attributed to the production of isothiocyanates (ITCs) following the action of myrosinase on glucosinolates (GSLs). Different ITCs are formed from different GSLs, depending on the plant species. To better understand the potential of ITCs, eight cultivars from three Brassicaceae species were investigated as biofumigation crops to control the root knot nematode Meloidogyne hapla. Since results were inconsistent, the nematicidal effect of selected ITCs were further evaluated in vitro. Based on its nematicidal potential, allyl ITC (AITC) was specifically investigated under different soil:sand compositions. A significantly lower nematicidal activity was observed in soil compared to sand. AITC was also evaluated as an additive to the biofumigation in a greenhouse trial. Its supplementation to the biofumigation process with Brassica juncea cv. Terrafit controlled M. hapla, while no control was observed using Raphanus sativus $\mathrm{cv}$. Defender. Thus, the success of biofumigation seems to be strongly dependent on the soil characteristics and the ITC produced during the biofumigation process. Therefore, the supplementation of AITC in combination with the right cover crop can improve the biofumigation process to control M. hapla.
\end{abstract}

Keywords: biofumigation; isothiocyanate; glucosinolate; plant-parasitic nematodes; root knot nematode; nematicides

\section{Introduction}

Chemical fumigants have been frequently used to protect high value crops from plant-parasitic nematodes (PPN). With stricter legislations and the ban of nematicides harmful to humans and the environment, the search for alternative methods was intensified [1-3].

The use of plant-based fumigation appears as an environmentally-friendly management strategy to control PPN $[4,5]$. This so-called biofumigation makes use of a natural plant defense mechanism of the Brassicaceae family producing the secondary metabolites glucosinolates (GSLs). More than 200 different GSLs are known, which are derived from glucose and amino acids containing sulfur and nitrogen [6,7]. After the damage of the plant tissue, GSLs stored in the vacuoles are hydrolyzed through the enzyme myrosinase (Thioglucosidase: EC 3.2.1.147), stored in myrosin grains (myrosin cells), and then converted into toxic isothiocyanates (ITCs) [7,8]. If, as a result of an attack by pests or pathogens, plant cells are destroyed, ITCs are released and repel or kill the invading organism. Sustainable agriculture systems make use of this chemical reaction by mechanically macerating and incorporating cover crops rich in GSL to induce ITC production for biofumigation [9]. 
Numerous studies have demonstrated the toxicity of ITCs to PPN $[4,5,10]$ and different effects were observed according to the nematode genus/species [11-13]. For example, allyl isothiocyanate (AITC; IUPAC name 3-Isothiocyanatoprop-1-ene) has a higher toxicity against root knot nematodes (Meloidogyne spp.) compared to phenyl isothiocyanate. Within Meloidogyne, the ITCs butenyl and 4-methylthiobutyl had a higher toxicity against $M$. incognita than $M$. javanica $[13,14]$. If biofumigation crops are used in praxis to control PPN, results can be contradictory $[5,10,15]$. Some studies demonstrated significant nematode suppression [16,17], while others showed only minor or no effects on PPN [18-20]. An alternative for growing biofumigation crops could be the application of Brassica-based seedmeal [21,22] or the use of a biological product containing mustard and chili pepper extracts, with AITC as nematicidal active compound (Dazitol ${ }^{\circledR} \_3.7 \%$ AITC) [23]. Both approaches were successfully used to control M. incognita and Pratylenchus penetrans [21,22].

The nematicidal effect of biofumigation is generally attributed to the effect of the ITCs concentration released by the plants. However, as shown by Vervoort et al. [19] under field conditions, the ITCs concentration is generally too low to account for the nematicidal effect. Besides, no GSL-containing plants express nematicidal effects after maceration and incorporation into the soil, most likely due to unspecific effects associated with the degradation of the organic matter or mechanical disturbance during incorporation.

Since ITCs are toxic to nematodes in vitro, the question remains how GSL-containing plants can successfully be used to control PPN [4,5]. The objectives of this study were to investigate: (1) the biofumigation performance in the field of different Brassicaceae cultivars on PPN; (2) the effect of soil composition on the efficacy of AITC to control Meloidogyne hapla; and (3) if co-application of biofumigation by two Brassica species with AITC can enhance control efficacy towards M. hapla. In this sense, an accumulated nematicidal effect due to the supplementation of ITC in combination with the right cover crop would potentially foster the biofumigation process to control $M$. hapla, retain plant nutrients and add organic matter to the soil.

\section{Results}

\subsection{Effect of Biofumigation to Control M. hapla under Field Conditions}

The biofumigation process took place at early flowering to flowering depending on the plant species/cultivar and the average fresh weight production ranged between 16.3 and $29.5 \mathrm{~kg} / \mathrm{m}^{2}$ depending on the Brassicaceae cultivars (Table S1). The total GSL concentration ranged between 10.1 (Terraplus) and $18.9 \mu \mathrm{mol} / \mathrm{g}$ dry matter (Defender) (Table S1). Initial population (Pi) densities of M. hapla ranged from 24 (Luna) to 1478 (Terrafit) J2/100 mL of soil and final population (Pf) densities from 36 (Defender) to 1150 (Energy) J2/100 $\mathrm{mL}$ of soil (Table 1). This resulted in no significant different multiplication rates (Pf/Pi) varying between 0.72 (Terrafit) and 1.88 (Energy and Luna) despite that Energy and Terrafit have a similar GSL concentration (12.99 and $13.5 \mu \mathrm{mol} / \mathrm{g}$, respectively) and sinigrin as the most abundant GSL (Table S1).

A reduction in $M$. hapla population $(\mathrm{Pf} / \mathrm{Pi}<1)$ was observed for Terrafit, Terraplus, Defender, Adagio, and black fallow. All other cultivars caused an increase in the population density of M. hapla (Table 1).

\subsection{In Vitro Effect of Different Isothiocyanates on M. hapla Motility}

The effect of different commercially available isothiocyanates on $M$. hapla $\mathrm{J} 2$ was evaluated in vitro. All ITCs tested significantly reduced J2 activity (Table 2), which was directly related to increasing concentrations and exposure times. The strongest nematicidal activity was observed for benzyl ITC, which caused even at the lowest concentration $(0.1 \mu \mathrm{mol} / \mathrm{mL}) 100 \%$ inactivity within $24 \mathrm{~h}$. The second most active compound was phenyl ITC with $95.8 \%$ inactivity, followed by butyl ITC and AITC with $74.2 \%$ and $72.3 \%$ inactivity after $24 \mathrm{~h}$ of exposure. Except for butyl ITC, all tested ITCs caused complete inactivity following $24 \mathrm{~h}$ exposure at the highest concentration $(10 \mu \mathrm{mol} / \mathrm{mL})$. Regarding the effect of 
increasing concentrations, 2-phenylethyl ITC showed the lowest effect on J2 with 59.3\% inactivity after $3 \mathrm{~h}$ at $10 \mu \mathrm{mol} / \mathrm{mL}$ (Table 2$)$.

Table 1. Initial (Pi) and final population (Pf) densities and multiplication rates (Pf/Pi) of Meloidogyne hapla for eight cultivars comprising three Brassicaceae species, namely Brassica juncea (BJ), Sinapis alba (SA), and Raphanus sativus (RS), in comparison to black fallow included as control $(n=4)$.

\begin{tabular}{ccccc}
\hline \multicolumn{2}{c}{ Cultivars } & $\mathbf{P i}$ & $\mathbf{P f}$ & $\mathbf{P f} / \mathbf{P i}$ \\
\hline \multirow{3}{*}{ BJ } & Energy & $612 \pm 353$ & $1150 \pm 438$ & 1.88 \\
\cline { 2 - 5 } & Terrafit & $1478 \pm 961$ & $1070 \pm 624$ & 0.72 \\
\cline { 2 - 5 } & Terraplus & $737 \pm 605$ & $567 \pm 471$ & 0.77 \\
\hline \multirow{2}{*}{ SA } & Luna & $24 \pm 32$ & $45 \pm 15$ & 1.88 \\
\cline { 2 - 5 } & Accent & $51 \pm 22$ & $54 \pm 48$ & 1.06 \\
\hline \multirow{3}{*}{ RS } & Defender & $39 \pm 26$ & $36 \pm 42$ & 0.92 \\
\cline { 2 - 5 } & Adagio & $140 \pm 135$ & $128 \pm 83$ & 0.91 \\
\cline { 2 - 5 } & Colonel & $171 \pm 145$ & $232 \pm 99$ & 1.36 \\
\hline & Fallow & $87 \pm 118$ & $82 \pm 105$ & 0.94 \\
\hline
\end{tabular}

Table 2. Effect of different isothiocyanates at different concentrations and exposure times on Meloidogyne hapla second-stage juvenile's motility, with and without recovery in water (w.i.).

\begin{tabular}{|c|c|c|c|c|c|}
\hline \multirow{2}{*}{$\begin{array}{c}\text { ITC } \\
\text { Concentration }\end{array}$} & \multirow[t]{2}{*}{ Exposure Time } & \multicolumn{4}{|c|}{ Juvenile Inactivity (\%) } \\
\hline & & $\mathrm{H}_{2} \mathrm{O}$ & $0.1 \mu \mathrm{mol} / \mathrm{mL}$ & $1 \mu \mathrm{mol} / \mathrm{mL}$ & $10 \mu \mathrm{mol} / \mathrm{mL}$ \\
\hline \multirow{2}{*}{ Allyl ITC } & $3 \mathrm{~h}$ (w.i.) & $2.2^{\mathrm{a} 1}\left(1.9^{\mathrm{a}}\right)$ & $79.7^{\mathrm{b} 1}\left(75.0^{\mathrm{b}}\right)$ & $95.8^{\mathrm{b} 1}\left(100.0^{\mathrm{b}}\right)$ & $100.0^{\mathrm{b} 1}\left(100.0^{\mathrm{b}}\right)$ \\
\hline & 24 h (w.i.) & $2.3^{\mathrm{a} 1}\left(2.4^{\mathrm{a}}\right)$ & $72.3^{\mathrm{b} 1}\left(77.2^{\mathrm{b}}\right)$ & $99.8^{\mathrm{b} 1}\left(100.0^{\mathrm{b}}\right)$ & $100.0^{\mathrm{b} 1}\left(100.0^{\mathrm{b}}\right)$ \\
\hline \multirow{2}{*}{ Benzyl ITC } & $3 \mathrm{~h}$ (w.i.) & $1.2^{\mathrm{a} 1}\left(1.2^{\mathrm{a}}\right)$ & $94.3^{\mathrm{b} 1}\left(99.8^{\mathrm{b}}\right)$ & $97.8^{\mathrm{c} 1}\left(99.7^{\mathrm{b}}\right)$ & $100.0^{\mathrm{c} 1}\left(100.0^{\mathrm{b}}\right)$ \\
\hline & 24 h (w.i.) & $1.2^{\mathrm{a} 1}\left(1.2^{\mathrm{a}}\right)$ & $100.0^{\mathrm{b} 2}\left(100.0^{\mathrm{b}}\right)$ & $100.0^{\mathrm{b} 2}\left(100.0^{\mathrm{b}}\right)$ & $100.0^{\mathrm{b} 1}\left(97.7^{\mathrm{b}}\right)$ \\
\hline \multirow{2}{*}{ Butyl ITC } & $3 \mathrm{~h}$ (w.i.) & $1.2^{\mathrm{a} 1}\left(2.0^{\mathrm{a}}\right)$ & $50.8^{\mathrm{b} 1}\left(15.3^{\mathrm{b} *}\right)$ & $71.8^{\mathrm{c} 1}\left(44.5^{\mathrm{c} *}\right)$ & $87.3^{\mathrm{d} 1}\left(96.3^{\mathrm{d}}\right)$ \\
\hline & 24 h (w.i.) & $2.5^{\mathrm{a} 1}\left(1.8^{\mathrm{a}}\right)$ & $74.2^{\mathrm{b} 2}\left(12.8^{\mathrm{b} *}\right)$ & $86.3^{\mathrm{c} 2}\left(68.2^{\mathrm{c} *}\right)$ & $98.7^{\mathrm{d} 2}\left(99.8^{\mathrm{d}}\right)$ \\
\hline \multirow{2}{*}{ Ethyl ITC } & $3 \mathrm{~h}$ (w.i.) & $1.2^{\mathrm{a} 1}\left(2.0^{\mathrm{a}}\right)$ & $25.2^{\mathrm{b} 1}\left(14.3^{\mathrm{b} *}\right)$ & $91.0^{\mathrm{c} 1}\left(82.2^{\mathrm{c} *}\right)$ & $99.3^{\mathrm{c} 1}\left(99.3^{\mathrm{d}}\right)$ \\
\hline & $24 \mathrm{~h}$ (w.i.) & $2.5^{\mathrm{a} 1}\left(1.8^{\mathrm{a}}\right)$ & $27.7^{\mathrm{b} 1}\left(6.8^{\mathrm{a} *}\right)$ & $99.2^{\mathrm{c} 2}\left(57.2^{\mathrm{b} *}\right)$ & $100.0^{\mathrm{c} 1}\left(100.0^{\mathrm{c}}\right)$ \\
\hline \multirow{2}{*}{ Methyl ITC } & $3 \mathrm{~h}$ (w.i.) & $1.2^{\mathrm{a} 1}\left(2.0^{\mathrm{a}}\right)$ & $4.0^{\mathrm{a} 1}\left(5.7^{\mathrm{a}}\right)$ & $79.2^{\mathrm{b} 1}\left(44.2^{\mathrm{b} *}\right)$ & $99.3^{\mathrm{b} 1}\left(100.0^{\mathrm{c}}\right)$ \\
\hline & $24 \mathrm{~h}$ (w.i.) & $2.5^{\mathrm{a} 1}\left(1.8^{\mathrm{a}}\right)$ & $12.0^{\mathrm{b} 2}\left(11.8^{\mathrm{a}}\right)$ & $89.3^{\mathrm{c} 2}\left(47.3^{\mathrm{b} *}\right)$ & $100.0^{\mathrm{d} 1}\left(100.0^{\mathrm{c}}\right)$ \\
\hline \multirow{2}{*}{ Phenyl ITC } & $3 \mathrm{~h}$ (w.i.) & $1.3^{\mathrm{a} 1}\left(1.3^{\mathrm{a}}\right)$ & $55.5^{\mathrm{b} 1}\left(52.2^{\mathrm{b}}\right)$ & $98.0^{\mathrm{c} 1}\left(90.3^{\mathrm{c} *}\right)$ & $99.7^{\mathrm{c} 1}\left(99.3^{\mathrm{c}}\right)$ \\
\hline & 24 h (w.i.) & $1.0^{\mathrm{a} 1}\left(2.0^{\mathrm{a}}\right)$ & $95.8^{\mathrm{b} 2}\left(73.0^{\mathrm{b} *}\right)$ & $99.5^{\mathrm{c} 1}\left(96.0^{\mathrm{c} *}\right)$ & $100.0^{\mathrm{c} 1}\left(100.0^{\mathrm{c}}\right)$ \\
\hline \multirow{2}{*}{ 2-phenylethyl ITC } & $3 \mathrm{~h}$ (w.i.) & $1.3^{\mathrm{a} 1}\left(1.3^{\mathrm{a}}\right)$ & $5.7^{\mathrm{ab} 1}\left(6.8^{\mathrm{a} * *}\right)$ & $21.2^{\mathrm{b} 1}\left(75.0^{\mathrm{b} * *}\right)$ & $59.3^{\mathrm{c} 1}\left(99.3^{\mathrm{c}}\right)$ \\
\hline & $24 \mathrm{~h}$ (w.i.) & $1.0^{\mathrm{a} 1}\left(2.0^{\mathrm{a}}\right)$ & $16.8^{\mathrm{b} 2}\left(38.7^{\mathrm{b} * *}\right)$ & $89.8^{c 2}\left(98.3^{c * *}\right)$ & $100.0^{c 2}\left(99.8^{c}\right)$ \\
\hline
\end{tabular}

M. hapla second-stage juveniles (J2) response to $0.1,1$, and $10 \mu \mathrm{mol} / \mathrm{mL}$ of different isothiocyanates (ITCs) exposed for 3 and $24 \mathrm{~h}$, followed by nematode washing in water $\left(\mathrm{H}_{2} \mathrm{O}\right)$ and a $24 \mathrm{~h} \mathrm{H}_{2} \mathrm{O}$ recovery assay. Different superscript letters indicate significantly inactive $\mathrm{J} 2$ (movement affected, inhibited, or immobile) in percentage (\%) over the concentrations calculated using a one-way ANOVA with post-hoc Tukey HSD test $(n=6)$. Different superscripted numbers indicate significantly inactive $\mathrm{J} 2$ in percentage (\%) over time ( 3 and $24 \mathrm{~h}$ ), while significant $\mathrm{H}_{2} \mathrm{O}$ recovery is indicated by an *, and significant persistent inactivation on $\mathrm{J} 2$ after the $\mathrm{H}_{2} \mathrm{O}$ recovery attempt is indicated by **, analyzed by $t$-test. w.i., $\mathrm{H}_{2} \mathrm{O}$ incubation, indicating the recovery assay. $p<0.05$.

Following the various treatments, J2 were washed and incubated in water for $24 \mathrm{~h}$. Significant recovery of J2 was observed for butyl ITC, ethyl ITC, methyl ITC, and phenyl ITC at 0.1 and $1 \mu \mathrm{mol}$, but not at $10 \mu \mathrm{mol}$. The nematodes treated with $0.1 \mu \mathrm{mol} / \mathrm{mL}$ of butyl ITC showed the strongest recovery effect with a reduction from $50.8 \%$ to $15.3 \%$ inactive J2 after $3 \mathrm{~h}$ of exposure, and from $74.2 \%$ to $12.8 \%$ inactive $\mathrm{J} 2$ after $24 \mathrm{~h}$ of exposure. In contrast to all other ITCs tested, J2 treated 
with 2-phenylethyl ITC did not show recovery and J2 inactivity significantly increased after washing and incubation in water (Table 2).

\subsection{Long Term In Vitro Effect of Aallyl Isothiocyanate towards M. hapla}

All AITC concentrations tested affected M. hapla J2 motility in vitro, in comparison to the control (Table 3). After 1, 5, 10, and 20 days, J2 motility was affected by all AITC concentrations and the increase of AITC concentrations caused an increase on the immotility of J2. After one and five days of exposure to 5 and $10 \mu \mathrm{mol} / \mathrm{mL}$ of AITC, J2 motility was affected or J2 were immotile, while, at the highest concentrations of 20 and $40 \mu \mathrm{mol} / \mathrm{mL}$ AITC, all J2 were immotile even the first day of exposure. The lethal concentrations required to kill $50 \%\left(\mathrm{LC}_{50}\right)$ of $\mathrm{J} 2$ ranged between $0.19 \mu \mathrm{mol} / \mathrm{mL}$ at Day 5 and $0.07 \mu \mathrm{mol} / \mathrm{mL}$ at Day 7 .

Table 3. Effect of allyl isothiocyanate (AITC) on Meloidogyne hapla second-stage juveniles (J2) after 1, 5, 10 , and 20 days of exposure and gall index (GI) of cucumber roots three weeks after inoculation with J2 treated with the respective AITC concentrations.

\begin{tabular}{|c|c|c|c|c|c|c|}
\hline Exposure Period & AITC $\mu \mathrm{mol} / \mathrm{mL}$ & N (\%) & A $(\%)$ & I $(\%)$ & $\mathrm{LC}_{50}(\mu \mathrm{mol} / \mathrm{mL})$ & GI \\
\hline \multirow{7}{*}{ Day 1} & control & 93.7 & 4.7 & 1.7 & \multirow{7}{*}{$0.15(0.061-0.369)$} & $6.00 \pm 0^{a}$ \\
\hline & 0.01 & 89.7 & 9.3 & 1.0 & & $5.50 \pm 0.5^{a}$ \\
\hline & 0.1 & 38.3 & 58.0 & 3.7 & & $4.25 \pm 0.5^{b}$ \\
\hline & 1 & 1.0 & 89.7 & 9.3 & & $3.00 \pm 0.8^{c}$ \\
\hline & 5 & 0.0 & 34.7 & 65.3 & & $0^{d}$ \\
\hline & 10 & 0.0 & 6.3 & 93.7 & & $0^{d}$ \\
\hline & $20-40$ & 0.0 & 0.0 & 100 & & $0^{d}$ \\
\hline \multirow{7}{*}{ Day 5} & control & 92.7 & 3.3 & 4.0 & \multirow{7}{*}{$0.19(0.07-0.519)$} & $6.00 \pm 0^{a}$ \\
\hline & 0.01 & 74.3 & 20.7 & 5.0 & & $5.75 \pm .05^{\mathrm{a}}$ \\
\hline & 0.1 & 69.3 & 25.7 & 5.0 & & $4.75 \pm 0.5^{b}$ \\
\hline & 1 & 19.3 & 45.3 & 35.3 & & $2.50 \pm 0.5^{\mathrm{c}}$ \\
\hline & 5 & 0.0 & 16.0 & 84.0 & & $0^{d}$ \\
\hline & 10 & 0.0 & 3.7 & 96.3 & & $0^{d}$ \\
\hline & $20-40$ & 0.0 & 0.0 & 100 & & $0^{d}$ \\
\hline \multirow{5}{*}{ Day 10} & control & 91.3 & 4.0 & 4.7 & \multirow{5}{*}{$0.10(0.036-0.335)$} & $5.50 \pm 0.5^{\mathrm{a}}$ \\
\hline & 0.01 & 64.3 & 24.0 & 11.7 & & $5.00 \pm 0.8^{a}$ \\
\hline & 0.1 & 60.0 & 30.0 & 10.0 & & $4.75 \pm 0.5^{\mathrm{a}}$ \\
\hline & 1 & 5.7 & 33.3 & 61.0 & & $2.50 \pm 0.5^{b}$ \\
\hline & 5 to 40 & 0.0 & 0.0 & 100 & & $0^{c}$ \\
\hline \multirow{5}{*}{ Day 20} & control & 73.7 & 15.3 & 11.0 & \multirow{5}{*}{$0.07(0.025-0.184)$} & $4.00 \pm 0.8^{a}$ \\
\hline & 0.01 & 55.3 & 29.3 & 15.3 & & $3.75 \pm 0.5^{\mathrm{a}}$ \\
\hline & 0.1 & 46.3 & 36.7 & 17.0 & & $3.50 \pm 0.5^{a b}$ \\
\hline & 1 & 4.3 & 32.7 & 63.0 & & $2.50 \pm 0.5^{b}$ \\
\hline & 5 to 40 & 0.0 & 0.0 & 100 & & $0^{\mathrm{c}}$ \\
\hline
\end{tabular}

Normal (N), affected (A), and immotile (I) second-stage juveniles (J2) are displayed in percentage $(\%)(n=3)$. Data for A and I J2 were pooled and log-transformed for $\mathrm{LC}_{50}$ (Lethal concentration, 50\%) analysis using a linear regression model. Exposed J2 were inoculated on Cucumis sativus seedlings and root gall indexing (GI) according to Zeck [24] was determined three weeks later $(n=4)$. Means followed by different superscript letters within the same column indicate significant differences calculated using a one-way ANOVA with post-hoc Tukey HSD test. $p<0.05$. 
In a second approach of this experiment, the AITC treated J2 were inoculated on cucumber seedlings. Three weeks after inoculation, the highest gall index of 6 was obtained in the control for J2 at one day of exposure. With increasing exposure time, the gall index decreased to reach a value of 4 after 20 days of inoculation. J2 exposed to $0.01,0.1$, and $1 \mu \mathrm{mol} / \mathrm{mL}$ of AITC were still able to infect and cause root galling, regardless the number of days of exposure (Table 3). J2 treated with concentrations $>5 \mu \mathrm{mol} / \mathrm{mL}$ of AITC did not cause any galling. In comparison to the AITC concentration, the exposure time had little effect on the galling, although there was a slight tendency to gall index decrease with increasing exposure time.

\subsection{Effect of Soil Composition on the Control Efficacy of Allyl Isothiocyanate towards M. hapla}

To evaluate the effect of soil composition and organic matter content on the nematicidal potential of AITC to control M. hapla, we tested different sand:soil mixtures and an organic potting substrate (Table 4). In general, the highest gall index was achieved in the control with values ranging between 4.8 and 5.6 depending on the soil composition (Table 4). With increasing AITC concentrations, gall index was reduced, except for the potting substrate. This effect was most pronounced in sand where concentrations $>20 \mu \mathrm{mol} / \mathrm{mL}$ inhibited nematode development. With increasing ratios of soil, the nematicidal effect of AITC was reduced and the gall index increased. For example, the gall index of cucumber roots grown in sand treated with $5 \mu \mathrm{mol} / \mathrm{mL}$ AITC was 2.2 compared to 4.8 in field soil. For soil, only the highest AITC concentration caused a significant reduction in gall index. Besides the control, the overall highest gall index was observed in the organic potting substrate (Table 4). Regardless of the AITC concentration, the gall index ranged between $5.0(20$ and $40 \mu \mathrm{mol} / \mathrm{mL})$ and 5.4 $(10 \mu \mathrm{mol} / \mathrm{mL})$ and thus AITC does not seem to affect $M$. hapla parasitism under these conditions.

Table 4. Impact of different sand:soil compositions and organic potting substrate on the efficacy of allyl isothiocyanate (AITC) to reduce the gall index* caused by Meloidogyne hapla on Cucumis sativus.

\begin{tabular}{|c|c|c|c|c|c|c|}
\hline \multirow{2}{*}{$\begin{array}{c}\text { AITC } \\
\mu \mathrm{mol} / \mathrm{mL}\end{array}$} & \multirow{2}{*}{ Sand } & \multicolumn{3}{|c|}{ Sand:Soil Mix } & \multirow{2}{*}{ Soil } & \multirow{2}{*}{$\begin{array}{l}\text { Potting } \\
\text { Substrate }\end{array}$} \\
\hline & & $2: 1$ & $1: 1$ & $1: 2$ & & \\
\hline Control & $5 \pm 0.7^{\mathrm{a} 1}$ & $5 \pm 0.7^{a 1}$ & $5.6 \pm 0.5^{a 1}$ & $5.2 \pm 1.0^{\mathrm{a} 1}$ & $4.8 \pm 1.0^{\mathrm{a} 1}$ & $5 \pm 0.7^{a 1}$ \\
\hline 1 & $3.2 \pm 0.8^{\mathrm{b} 1}$ & $3.6 \pm 0.8^{a b 12}$ & $4.2 \pm 0.4^{b 13}$ & $4.6 \pm 0.5^{a 23}$ & $5 \pm 0.7^{a 3}$ & $5.2 \pm 0.4^{\mathrm{a} 3}$ \\
\hline 5 & $2.2 \pm 0.8^{\mathrm{b} 1}$ & $3.4 \pm 0.5^{b 2}$ & $4.2 \pm 0.4^{\mathrm{b} 23}$ & $4 \pm 0.9^{a 23}$ & $4.8 \pm 0.4^{\mathrm{a} 3}$ & $5.2 \pm 0.4^{\mathrm{a} 3}$ \\
\hline 10 & $0.6 \pm 0.8^{\mathrm{c} 1}$ & $2.6 \pm 0.8^{b c 2}$ & $3.4 \pm 0.5^{b c 23}$ & $4 \pm 0.7^{\mathrm{a} 234}$ & $4.4 \pm 0.8^{\mathrm{ab} 34}$ & $5.4 \pm 0.5^{a 4}$ \\
\hline 20 & $0^{\mathrm{c} 1}$ & $2.6 \pm 0.8^{b c 2}$ & $3 \pm 0.7^{\operatorname{cd} 23}$ & $3.6 \pm 0.8^{a b 234}$ & $4.4 \pm 1.1^{\mathrm{ab} 34}$ & $5 \pm 0.7^{a 4}$ \\
\hline 40 & $0^{\mathrm{c} 1}$ & $1.2 \pm 0.4^{\mathrm{c} 2}$ & $2 \pm 0.7^{\mathrm{d} 23}$ & $2.25 \pm 0.5^{b 234}$ & $3 \pm 0.7^{b 34}$ & $5 \pm 0.7^{\mathrm{a} 5}$ \\
\hline
\end{tabular}

* Gall index on a 0-10 scale according to Zeck [24]. Means followed by different superscript letters within the same column indicate significant differences. Means followed by different numbers within the same row indicate significant differences calculated using a one-way ANOVA with post-hoc Tukey HSD test $(n=5) . p<0.05$.

\subsection{Allyl Isothiocyanate as Additive to the Biofumigation Process to Control M. hapla}

Three cover crops were supplemented with different concentrations of AITC at biofumigation and M. hapla population density was evaluated two weeks later. The average fresh weight production in the trays were $10.6 \mathrm{~kg} / \mathrm{m}^{2}$ for Terrafit and $12.2 \mathrm{~kg} / \mathrm{m}^{2}$ for Defender (Table S2). M. hapla densities in the non-treated crops ranged between 81.2 (Defender) and 92.2 (cover crop mix) J2/100 mL soil (Table 5).

The number of $\mathrm{J} 2$ was significantly higher on crops than in the fallow treatment $(36.3 \mathrm{~J} 2 / 100 \mathrm{~mL}$ soil) representing the natural decline of $M$. hapla. Supplement of Defender or the cover crop mix with AITC during biofumigation did not result in a reduction of $M$. hapla J2 compared to the non-treated control, regardless of the concentration. In contrast, supplement of Terrafit with AITC at the highest concentration $(60 \mu \mathrm{mol} / \mathrm{mL})$ caused a significant reduction of $\mathrm{J} 2$ by $33.4 \%$ in comparison to the control. The three crops used for biofumigation did not differ in their effect on M. hapla J2 density except at 
$60 \mu \mathrm{mol} / \mathrm{mL}$ AITC supplement (Terrafit showed the significantly lowest $M$. hapla population density with 57.1 J2/100 mL soil, followed by Defender with 78.5 J2/100 mL soil).

Table 5. Effect of allyl isothiocyanate supplementation on the efficacy of the biofumigation potential of three cover crops to control Meloidogyne hapla.

\begin{tabular}{|c|c|c|c|c|c|c|}
\hline \multirow[b]{2}{*}{ Cultivars } & \multicolumn{5}{|c|}{$\begin{array}{l}\text { Meloidogyne hapla Juveniles (J2/100 mL soil) after AITC Treatment } \\
(\mu \mathrm{mol} / \mathrm{mL})\end{array}$} & \multirow{2}{*}{$\begin{array}{c}\text { J2 Reduction * } \\
\%\end{array}$} \\
\hline & 0 & 10 & 20 & 40 & 60 & \\
\hline $\begin{array}{l}\text { Brassica juncea } \\
\text { cv Terrafit }\end{array}$ & $85.7 \pm 6.6^{a}$ & $84.5 \pm 8.5^{\mathrm{a}}$ & $84.3 \pm 8.3^{a}$ & $74.7 \pm 8.1^{a}$ & $57.1 \pm 11.6^{\mathrm{a} *}$ & 33.4 \\
\hline $\begin{array}{l}\text { Raphanus sativus } \\
\text { cv Defender }\end{array}$ & $81.2 \pm 7.7^{\mathrm{a}}$ & $78.7 \pm 5.8^{\mathrm{a}}$ & $84.3 \pm 7.1^{a}$ & $83.5 \pm 6.7^{\mathrm{a}}$ & $78.5 \pm 5.6^{b}$ & 3.3 \\
\hline Cover crop mix & $92.2 \pm 8.2^{\mathrm{a}}$ & - & $94.5 \pm 5.8^{\mathrm{a}}$ & $94.4 \pm 5^{a}$ & $93.6 \pm 5.7^{c}$ & 0.0 \\
\hline Fallow & $36.3 \pm 10.2^{b}$ & - & - & - & - & \\
\hline
\end{tabular}

Means followed by the same superscript letter within a column indicate significant differences between the crops. The asterisks indicate significant differences between different allyl isothiocyanate concentration within a crop calculated using a one-way ANOVA with post-hoc Tukey HSD test $(n=6) . p<0.05 .{ }^{*} \mathrm{~J} 2$ reduction by comparison between 0 and $60 \mu \mathrm{mol} / \mathrm{mL}$ AITC treatment-no data available.

\section{Discussion}

\subsection{Effect of Biofumigation to Control M. hapla under Field Conditions}

The efficacy of biofumigation to control PPN is discussed controversially among experts. Published reports on biofumigation cover the entire span from successful to no nematode control $[4,5]$. This is reflected by our own biofumigation data, where $B$. juncea $\mathrm{cv}$. Terrafit caused a reduction in M. hapla reproduction, whereas Sinapis alba cv. Luna and B. juncea cv. Energy did not.

Within the field trial, the content and concentration of GSL produced by the selected plants were in line with previously reported results $[19,25,26]$. However, Energy supported reproduction of M. hapla with a multiplication rate of 1.8 , whereas Terrafit had a multiplication rate of 0.72 and thus caused a decrease in $M$. hapla population density. This indicates that the observed reduction of M. hapla by Terrafit cannot be explained by its GSL content, since this parameter was similar for both cultivars.

Nevertheless, it is well documented that the origin and composition of ITCs is relevant for the biofumigation success and can result in crop yield increases up to $30 \%$ under optimum conditions [27].

\subsection{In Vitro Effect of Different Isothiocyanates on M. hapla Motility}

Generally, the nematicidal activity of the biofumigation process is attributed to the production and the chemical structure (e.g., aliphatic, aromatic, polar, or non-polar) of ITCs, as reported for various PPNs [11-14,28-32]. According to reports in the literature and confirmed by our results, AITC and benzyl ITC are among the most potent nematicidal ITCs in vitro [12-14]. In comparison to AITC and benzyl ITC, 2-phenylethyl ITC showed overall lower nematicidal activity, but it was the only ITC where the nematicidal activity increased even after the $\mathrm{J} 2$ were washed in water, indicating an enduring effect. A lower nematicidal activity of 2-phenylethyl ITC in comparison with AITC was also reported for M. javanica [13].

\subsection{Long Term In Vitro Effect of Allyl Isothiocyanate towards M. hapla}

At the concentration of $0.1 \mu \mathrm{mol} / \mathrm{mL}$ of AITC, significant reduced galling was only observed on Days 1 and 5, suggesting that the weaker J2 were more strongly affected by AITC at onset of the experiment. At $5 \mu \mathrm{mol} / \mathrm{mL}$ of AITC, only affected J2 were observed in vitro, and thus root knot formation did not occur. Therefore, some $M$. hapla might be affected by ITC during the biofumigation process and as a consequence are not infectious in the field, even though those $\mathrm{J} 2$ can be evaluated as normal or affected during a short in vitro nematicidal test. Based on the cucumber bioassay, a significant 
reduction in gall index was achieved at AITC concentrations of 0.1 and 1-5 days of incubation and of $1 \mu \mathrm{mol} / \mathrm{mL}$ or higher, independent of the incubation time. Overall, our AITC lethal concentration at $50 \%\left(\mathrm{LC}_{50}\right.$; ranging from 0.07 and $\left.0.19 \mu \mathrm{mol} / \mathrm{mL}\right)$ were within the range of a previous report for M. javanica [12] that measured a $\mathrm{LC}_{50}$ value of $0.10 \mu \mathrm{mol} / \mathrm{mL}$. However, it is important to mention that M. javanica J2 were exposed to AITC in sand [12] compared to water in our case, which might have had an influence on the nematicidal effect.

\subsection{Effect of Soil Composition on the Control Efficacy of Allyl Isothiocyanate towards M. hapla}

As is known from the literature, the effect of ITC varies greatly between different studies $[4,5]$. Major aspects contributing to this variation are assumed to be the soil type and organic matter content. Our results show that AITC activity increased with increasing sand content; this finding is in line with previous findings, where ITCs remained more active in sandy soil than in organic rich soil, or soil with a high clay contend [33-38]. Another important aspect to state is that autoclaved soil tends to have a higher AITC recovery than non-autoclaved soil $[33,39]$, suggesting that the microbial community present in the soil plays an important role in the degradation of AITC reducing its half-life.

Nevertheless, since steamed soil was used in our experiments, we can assume that clay particles and organic matter were the major components inhibiting AITC nematicidal potential, instead of microbial activity.

\subsection{Allyl Isothiocyanate as Additive to the Biofumigation Process to Control M. hapla}

As in the field experiment, the ITCs produced in the tray experiment were not sufficient to control M. hapla. Only after AITC was supplemented to the biofumigation, nematode control was achieved for B. juncea cv. Terrafit. The difference observed for B. juncea cv. Terrafit and R. sativus cv. Defender is due to their GSL amount and composition. While B. juncea mainly produces sinigrin, the precursor of AITC, R. sativus mainly produces 4-methylthiobutyl, the precursor of 4-methylthiobutyl ITC, which might be less effective to control M. hapla. Interestingly, according to Lazzeri et al. [14], 4-methylthiobutyl ITC and AITC had a similar immobilizing effect on M. incognita with a $\mathrm{LD}_{50}$ of 0.021 and $0.034 \mathrm{mM}$, respectively. However, it seems, that, only if additional AITC is applied to B. juncea cv. Terrafit, the AITC concentrations reach levels high enough to control M. hapla. Thus, supplementation of AITC during biofumigation with the cover crop B. juncea might be an alternative control option for M. hapla.

In the tray experiment, an effect of AITC towards M. hapla was only seen at the highest concentration of $60 \mu \mathrm{mol} / \mathrm{mL}$. This slightly conflicts with results from our previous test in soil where already $40 \mu \mathrm{mol} / \mathrm{mL}$ caused a significant reduction in root gall index caused by M. hapla. First, there is always variability in the distribution of AITC within the soil and the two concentrations are not that different. Second, the incorporation of the plant organic matter in the tray experiment might have buffered partly the AITC activity. These assumptions are supported due to the increased application of AITC in the tray experiment compared to the small soil experiment, where no control of $M$. hapla was seen for the cover crop mix and R. sativus cv. Defender. Furthermore, steamed soil was used for all the experiments, and, as described by Hanschen et al. [39], autoclaved soil significantly increases AITC half-life. The steamed soil used in the trays had few weeks to increase its bioactivity during the plant growth and watering, compared to the sand:soil experiment and, therefore, the microbial activity established might have had an additional effect on the nematicidal activity of the AITC, as described by Hanschen et al. [39].

\subsection{Allyl Isothiocyanate as Additive for Biofumigation in the Filed}

Our findings raised the question of whether the approach of a biofumigant crop in combination with the direct application of AITC can be used under field conditions. Based on the soil:sand experiment, the nematicidal activity depends on the soil type; the higher is the proportion of sand, the better is the effect. This is confirmed by a biofumigation study with $B$. juncea where a higher amount of AITC was extracted from sandy-loam soil compared to clay-loam soil [33]. Thus, the effect 
of direct application of AITC in combination with biofumigation on nematode control might be soil type dependent with a clear tendency of better effects in more sandy soils. This is in line with results from field studies in Florida on a Myakka fine sand containing 98\% sand, were AITC applications demonstrated good controlling effects on Meloidogyne spp. [40]. Those results are of particular interest since sandy soils are generally vulnerable to erosion. However, if biofumigation with the supplementation of AITC is applied during offseason, nematode and erosion control could be easily combined. However, for heavy soils, further research on AITC and other ITCs formulation is needed, to better understand nematode control under those conditions and to find control alternatives.

Since the average fresh weight of the two cultivars Terrafit and Defender was approximately half the amount in the greenhouse compared to the field, the biofumigation process might be more efficient under field conditions because of the higher plant biomass and thus higher ITC rates. Furthermore, as shown by recent kinetic model, ITC formation strongly depends on water availability and $\mathrm{pH}$ [41]. To define the optimum conditions, additional investigations to maximize the GSL conversion and to increase the ITCs formation in the field are required.

If the application of AITC in addition to the biofumigation process proved to be an efficient nematode control alternative, possible formulations and application systems have to be discussed. One option might be biological products containing AITC as the nematicidal active compound, such as Dazitol, showing promising results by controlling Meloidogyne spp. in tomato [23,42] and Globodera spp. in potato under field conditions [43]. A combination of plant biofumigation and the usage of botanical compounds (e.g., AITC) might have multiple benefits for the soil structure than solely a treatment with AITC. However, due to the broad-spectrum activity of ITCs, it is of utmost importance for all field studies to evaluate its side effects on non-target organisms and the microbiome in general $[44,45]$.

\section{Material and Methods}

\subsection{Nematode Inoculum and Isothiocyanates}

Meloidogyne hapla was maintained on tomato (Solanum lycopersicum) cv. Moneymaker under greenhouse conditions $\left(25 / 19^{\circ} \mathrm{C}, 60 \%\right.$ humidity, $15 / 9 \mathrm{~h}$ day night cycle). Freshly hatched second-stage juveniles (J2) were extracted from heavily galled root systems placed under a mist chamber $\left(22^{\circ} \mathrm{C}\right)[46]$. Hatched J2 were collected every day and stored at $6{ }^{\circ} \mathrm{C}$ until being used in experiments, but no longer than 10 days.

The ITCs allyl isothiocyanate, benzyl isothiocyanate, butyl isothiocyanate, ethyl isothiocyanate, methyl isothiocyanate, phenyl isothiocyanate, and 2-phenylethyl isothiocyanate were obtained from Sigma-Aldrich (St. Louis, MO, USA) and diluted with sterilized water to achieve the concentrations requested in the different experiments. For the allyl isothiocyanate (AITC) experiment in soil, the volumetric measure of the pots was used to calculate the concentration $(\mu \mathrm{mol} / \mathrm{mL})$ applied to the soil.

\subsection{Effect of Biofumigation to Control M. hapla under Field Conditions}

The field experiment was conducted at an organic farm with silty loam soil, in Ahlden, Lower Saxony, Germany. The experiment consisted of eight cultivars comprising 3 species from the family Brassicacea: Raphanus sativus (RS) cvs. Adagio, Colonel. and Defender; Brassica juncea (BJ) cvs. Terrafit, Terraplus. and Energy; and Sinapis alba (SA) cvs. Luna and Accent. Each cultivar was replicated 4 times. The biofumigation crops were planted in strips of $50 \mathrm{~m} \times 3 \mathrm{~m}$, and each strip was split into four plots of $12.5 \mathrm{~m} \times 3 \mathrm{~m}$. One strip was kept fallow and used as negative control. Seed density was $12 \mathrm{~kg} \mathrm{ha}^{-1}$ for Raphanus sativus cvs. Adagio, Colonel, and Defender; $15 \mathrm{~kg} \mathrm{ha}^{-1}$ for Brassica juncea cvs. Terrafit, Terraplus, and Energy; and $20 \mathrm{~kg} \mathrm{ha}^{-1}$ for Sinapis alba cvs. Luna and Accent, according to the seed companies' recommendations. The row distance for all crops was $13 \mathrm{~cm}$.

At harvest, all plants from the central $1 \mathrm{~m}^{2}$ of each plot were cut just above the soil surface and fresh and dry weights recorded. From the remaining plants in the plots, 10 plants were randomly 
selected, uprooted, frozen, and kept at $-80^{\circ} \mathrm{C}$. Freeze-dried material was homogenized to powder. A subsample $(200 \mathrm{mg})$ was solubilized in methanol:water $(70: 30, \mathrm{~V}: \mathrm{V})$, at $75^{\circ} \mathrm{C}$ and used for GSL extraction in a column stacked with DEAE A25 Sepahdex (CAS Number 12609-80-2, Sigma Aldrich, MO, USA). Converted desulfo-GSLs were used for HPLC-DAD analyzes at a wavelength of $229 \mathrm{~nm}$ to evaluate the composition and amount of GSLs produced, as described by Vervoort et al. [19]. GSL composition per hectare was calculated according to GSL concentration and plant biomass.

The biofumigation crops were chopped and incorporated into the top $20 \mathrm{~cm}$ of soil, using a tractor-driven flail mower and a rotary tiller. The soil surface was rolled to minimize the evaporation of ITCs. Soil samples were taken prior to planting and four weeks after incorporation of the plants in the soil. Each sample consisted of 30 soil cores per plot, taken from the top $20 \mathrm{~cm}$, using an auger of $2 \mathrm{~cm}$ inner diameter. The soil was sieved through a $2 \mathrm{~cm}$ mesh to remove stones and plant debris and mix the soil at the same time. Then, $250 \mathrm{~mL}$ soil aliquots were processed using the centrifugal flotation method supplemented with kaolin, as described in Hallmann and Subbotin [46]. PPN were counted under a light microscope at $40 \times$ magnification.

\subsection{In Vitro Effect of Different Isothiocyanates on M. hapla Motility}

The inhibition of $M$. hapla by ITCs was tested in vitro in 24-well plates $(n=6)$. Each well was filled with $0.5 \mathrm{~mL}$ nematode suspension containing $200 \mathrm{~J} 2 \mathrm{of} M$. hapla plus $0.5 \mathrm{~mL}$ of double strength isothiocyanate solutions to result in final concentrations of $0.1,1$, and $10 \mu \mathrm{mol} / \mathrm{mL}$. All seven ITCs listed above were tested at $20^{\circ} \mathrm{C}$ and well plates were kept in dark. Nematode motility was examined after 3 and $24 \mathrm{~h}$ under the light microscope at $40 \times$ magnification. The first $100 \mathrm{~J} 2$ were recorded as active or inactive, then rinsed with tap water, using a $20-\mu \mathrm{m}$ mesh sieve, and transferred to new 24 well plates containing tap water. Juveniles remaining inactive after $24 \mathrm{~h}$ in tap water were considered as dead.

\subsection{Long Term In Vitro Effect of Allyl Isothiocyanate towards M. hapla}

Because of the high toxicity of AITC and the fact that sinigrin as precursor of AITC occurs at high concentrations in Brassic juncea, AITC was selected for further studies on improving the control M. hapla. Four thousand M. hapla J2 were exposed to $0.01,0.1,1,5,10,20$, and $40 \mu \mathrm{mol} / \mathrm{mL}$ AITC at $20^{\circ} \mathrm{C}$ in dark and evaluated 1, 5, 10, and 20 days after exposure. For each concentration and time point, triplicates of $100 \mathrm{~J} 2$ each were evaluated and assigned according to the motility: normal motility, affected motility, and immotility (elongated). From the remaining J2, $4 \times 250 \mathrm{~J} 2$ from each concentration and time point were rinsed as mentioned above and separately inoculated on pre-germinated cucumber seedlings (Cucumis sativus $\mathrm{cv}$. Sprinter F1) in $30 \mathrm{~mL}$ pots $(n=4)$. The cucumber plants were grown in a growth chamber at $23{ }^{\circ} \mathrm{C} \pm 2{ }^{\circ} \mathrm{C}, 16 \mathrm{~h}$ photoperiod, and $60 \%$ relative humidity. After 21 days of inoculation, cucumber roots were washed and the gall index was determined on a $0-10$ scale [24].

\subsection{Effect of Soil Composition on the Control Efficacy of Allyl Isothiocyanate towards M. hapla}

The effect of the AITC treatment on M. hapla was evaluated using different soil compositions. The original field soil consisted of $4.3 \%$ humus, $15.9 \%$ clay, $58.7 \%$ silt, $25.4 \%$ sand, and $\mathrm{pH}$ of 6.8 was steamed at $65^{\circ} \mathrm{C}$ for $3 \mathrm{~h}$ before usage. This soil was mixed with different ratios of silver sand, to obtain sand:soil ratios of 1:0 (100\%), 2:1 (67\%), 1:1 (50\%), 1:2 (33\%), and 0:1 (0\%). Potting substrate FLORADUR ${ }^{\circledR} 10445$ (Floragard, Saterland, Germany) containing $90-100 \%$ peat was used to represent organic rich soil. Therefore, $60 \mathrm{~mL}$ pots ( 5 replicates/treatment) were filled with $50 \mathrm{~mL}$ soil/substrate, watered slightly, and inoculated with $5 \mathrm{~mL}$ water suspension containing $250 \mathrm{M}$. hapla J2. After $48 \mathrm{~h}$, $10 \mathrm{~mL}$ AITC solutions were added per pot to reach final concentrations of $1,5,10,20$, and $40 \mu \mathrm{mol} / \mathrm{mL}$. The AITC solution was applied on the soil surface and washed into the substrate with $10 \mathrm{~mL}$ of water. Finally, the pots were sealed with parafilm for optimum fumigation. After five days, to avoid phytotoxic effects, three-day-old cucumber seedlings were planted into the pots. Twenty-one days after planting, cucumber roots were washed and the root gall index assessed [24]. 


\subsection{Allyl Isothiocyanate as Additive to the Biofumigation Process to Control M. hapla}

The biofumigant cover crops Raphanus sativus (cv. Defender) and Brassica juncea (cv. Terrafit) and the non-biofumigant cover crop mix, UFA Maislegum mix (containing Trifolium hybridum, Medicago lupulina, T. incarnatum and T. repens) were grown in $56 \mathrm{~cm} \times 36 \mathrm{~cm} \times 17 \mathrm{~cm}$ trays, filled with $25 \mathrm{~L}$ of the same (field) soil as described above. The $0.2 \mathrm{~m}^{2}$ tray surface was seeded with either $0.6 \mathrm{~g}$ seeds of $B$. juncea cv. Terrafit, $1.2 \mathrm{~g}$ seeds of $R$. sativus cv. Defender or $0.52 \mathrm{~g}$ seeds of the cover crop mix. To mimic different $M$. hapla developmental stages at the time of the biofumigation process (e.g., eggs and J2), seedlings were inoculated with 10,000 and 5000 M. hapla J2 at 2 and 3 weeks after sowing, respectively. Two rows, each with 6 holes of $4 \mathrm{~cm}$ depth, were distributed over the trays. Each hole was inoculated with $833 \mathrm{~J} 2$ in $2 \mathrm{~mL}$ water resulting in a total number of 15,000 J2 per pot. After inoculation, trays were watered with a hand nozzle spray. Plants were grown in the greenhouse at $22 \pm 2{ }^{\circ} \mathrm{C}$ and $16 \mathrm{~h}$ photoperiod. The experiment was concluded (32 days post inoculation) after M. hapla completed one generation, which was achieved at a greenhouse temperate sum of $450{ }^{\circ} \mathrm{C}$ (above $8^{\circ} \mathrm{C}$ ) [47]. The aboveground plant material was cut and the fresh weight measured. The plant material was then macerated for $15 \mathrm{~s}$ by using an electrical string trimmer in a barrel. Macerated plant material was mixed with the soil, using a cement mixer. The soil and plant material mixtures were filled into $60 \mathrm{~L}$ plastic bags and placed back into the trays. Four different treatments with final AITC concentrations of 10, 20,40, and $60 \mu \mathrm{mol} / \mathrm{mL}$, and a control free of AITC were conducted. To assure that the concentration of AITC was the same for the $25 \mathrm{~L}$ of soil, the volumetric amount of the different AITC concentrations was prepared in bottles holding $2.5 \mathrm{~L}$, which was poured to the soil in the plastic bags. Plastic bags were rapidly sealed. Each treatment and control had 6 replicates. Two weeks after AITC treatment, 6 soil cores were taken from each pot, the soil was mixed and the nematodes extracted from 2 aliquots of $100 \mathrm{~mL}$ soil using the Oostenbrink dish technique [46]. The total number of extracted M. hapla $\mathrm{J} 2$ was counted.

\subsection{Data Analysis}

Statistical analyses were performed using the software SPSS 20, and the data tested for homogeneity of variances (Levenes test). The effect of ITCs on M. hapla J2 and root gall index data were $\log _{10}(x+1)$ transformed. Data were discriminated by one-way ANOVA with post-hoc Tukey HSD (Honestly Significant Difference) test $(p \leq 0.05)$. Differences of independent samples were calculated using a $t$-test. LC $_{50}$ (Lethal concentration, 50\%) was determined by polling the data of affected and immotile J2, log-transformed and analyzed by a linear regression model.

\section{Conclusions}

The biofumigation study reflected the inconclusive results regarding nematode control obtained from similar studies. While some Brassicacea successfully controlled M. hapla, others supported nematode multiplication. The nematicidal potential of ITCs was clearly demonstrated under in vitro conditions and different ITCs showed different degrees of effectivity. However, in soil systems, the ITC concentration did not seem to be high enough to control M. hapla. Only if the Brassica cover crop was supplemented with AITC at the time of biofumigation, an effect against M. hapla was observed. If application of AITC at time of biofumigation might be an effective method to control M. hapla under field conditions still needs to be evaluated.

Supplementary Materials: The following are available online at http://www.mdpi.com/2223-7747/9/5/603/s1. Table S1: Brassicaceae biomass production including the glucosinolate (GSL) content and quantity ( $\mu \mathrm{mol} / \mathrm{g}$ dry matter) in the tissue content of the shoots produced by eight cultivars of the species Brassica juncea (BJ), Sinapis alba (SA) and Raphanus sativus (RS), Table S2: Average fresh weight (FW) biomass production in $\mathrm{kg} / 0.2 \mathrm{~m}{ }^{2}$ by Raphanus sativus (cv. Defender), Brassica juncea (cv. Terrafit) and the cover crop UFA Maislegum mix (containing Trifolium hybridum, Medicago lupulina, Trifolium incarnatum, and Trifolium repens) produced during the greenhouse biofumigation tray experiment. 
Author Contributions: P.D. performed the experiments with input from J.H. P.D. and J.H. evaluated the findings and wrote the manuscript. All authors have read and agreed to the final version of the manuscript.

Funding: The field study was funded by the Bundesanstalt für Landwirtschaft und Ernährung (BLE) Projektträger Innovationsförderung (FKZ: 28-1-42.018-06). All other experiments received no external funding.

Acknowledgments: The authors acknowledge Mechthild Neuhaus and Falko Lange (Julius Kühn-Institut) and Jürgen Krauss, Erika Consoli, Reinhard Eder and Laurin Müller (Agroscope) for the technical support during the field and greenhouse trials. Andrea C. Ruthes and Eduard Holliger are acknowledged for proofreading the manuscript.

Conflicts of Interest: The authors declare no conflict of interest.

\section{References}

1. Ebone, L.A.; Kovaleski, M.; Deuner, C.C. Nematicides: History, mode, and mechanism action. Plant Sci. Today 2019, 6, 91-97. [CrossRef]

2. Stirling, G.R. Biological control of plant-parasitic nematodes. In Diseases of Nematodes, 1st ed.; Poinar, G.O., Jr., Jansson, H.-B., Eds.; CRC Press: Boca Raton, FL, USA, 2018; Volume 1, pp. 103-150.

3. Ntalli, N.G.; Caboni, P. Botanical nematicides: A review. J. Agric. Food Chem. 2012, 60, 9929-9940. [CrossRef] [PubMed]

4. Ntalli, N.; Caboni, P. A review of isothiocyanates biofumigation activity on plant parasitic nematodes. Phytochem. Rev. 2017, 16, 827-834. [CrossRef]

5. Dutta, T.K.; Khan, M.R.; Phani, V. Plant-parasitic nematode management via biofumigation using brassica and non-brassica plants: Current status and future prospects. Curr. Plant Biol. 2019, 17, 17-32. [CrossRef]

6. Clarke, D.B. Glucosinolates, structures and analysis in food. Anal. Methods 2010, 2, 310-325. [CrossRef]

7. Jeschke, V.; Burow, M. Glucosinolates. In eLS; John Wiley \& Sons, Ltd.: Hoboken, NJ, USA, 2018; pp. 1-8. [CrossRef]

8. Fenwick, G.R.; Heaney, R.K. Glucosinolates and their breakdown products in cruciferous crops, foods and feeding stuffs. Food Chem. 1983, 11, 249-271. [CrossRef]

9. Angus, F.; Gardner, A. Biofumigation: Isothiocyanates released from brassica roots inhibit growth of the take-all fungus. Plant Soil. 1994, 162, 107-112. [CrossRef]

10. Matthiessen, J.N.; Kirkegaard, J.A. Biofumigation and enhanced biodegradation: Opportunity and challenge in soilborne pest and disease management. Crit. Rev. Plant Sci. 2006, 25, 235-265. [CrossRef]

11. Yu, Q.; Tsao, R.; Chiba, M.; Potter, J. Selective nematicidal activity of allyl isothiocyanate. J. Food Agric. Environ. 2005, 3, 218-221. [CrossRef]

12. Zasada, I.A.; Ferris, H. Sensitivity of Meloidogyne javanica and Tylenchulus semipenetrans to isothiocyanates in laboratory assays. Phytopathology 2003, 93, 747-750. [CrossRef]

13. Wu, H.; Wang, C.J.; Bian, X.W.; Zeng, S.Y.; Lin, K.C.; Wu, B.; Zhang, G.A.; Zhang, X. Nematicidal efficacy of isothiocyanates against root-knot nematode Meloidogyne javanica in cucumber. Crop Prot. 2011, 30, 33-37. [CrossRef]

14. Lazzeri, L.; Curto, G.; Leoni, O.; Dallavalle, E. Effects of glucosinolates and their enzymatic hydrolysis products via myrosinase on the root-knot nematode Meloidogyne incognita (Kofoid et White) Chitw. J. Agric. Food Chem. 2004, 52, 6703-6707. [CrossRef] [PubMed]

15. Ploeg, A. Biofumigation to manage plant-parasitic nematodes. In Integrated Management and Biocontrol of Vegetable and Grain Crops Nematodes; Cianco, A., Mukerji, K.G., Eds.; Springer: Dordrecht, The Netherlands, 2008; pp. 239-248.

16. Mojtahedi, H.; Santo, G.S.; Wilson, J.H.; Hang, A.N. Managing Meloidogyne chitwoodi on potato with rapeseed as green manure. Plant Dis. 1993, 77, 42-46. [CrossRef]

17. Rahman, L.; Somers, T. Suppression of root knot nematode (Meloidogyne javanica) after incorporation of Indian mustard cv. Nemfix as green manure and seed meal in vineyards. Australas. Plant Pathol. 2005, 34, 77-83. [CrossRef]

18. Brolsma, K.M.; van der Salm, R.J.; Hoffland, E.; de Goede, R.G. Hatching of Globodera pallida is inhibited by 2-propenyl isothiocyanate in vitro but not by incorporation of Brassica juncea tissue in soil. Appl. Soil Ecol. 2014, 84, 6-11. [CrossRef] 
19. Vervoort, M.T.; Vonk, J.A.; Brolsma, K.M.; Schütze, W.; Quist, C.W.; de Goede, R.G.; Hoffland, E.; Bakker, J.; Mulder, C.; Hallmann, J.; et al. Release of isothiocyanates does not explain the effects of biofumigation with Indian mustard cultivars on nematode assemblages. Soil Biol. Biochem. 2014, 68, 200-207. [CrossRef]

20. Stirling, G.R.; Stirling, A.M. The potential of Brassica green manure crops for controlling root-knot nematode (Meloidogyne javanica) on horticultural crops in a subtropical environment. Aust. J. Exp. Agric. 2003, 43, 623-630. [CrossRef]

21. Curto, G.; Dallavalle, E.; Matteo, R.; Lazzeri, L. Biofumigant effect of new defatted seed meals against the southern root-knot nematode, Meloidogyne incognita. Ann. Appl. Biol. 2016, 169, 17-26. [CrossRef]

22. Zasada, I.A.; Meyer, S.L.F.; Morra, M.J. Brassicaceous seed meals as soil amendments to suppress the plant-parasitic nematodes Pratylenchus penetrans and Meloidogyne incognita. J. Nematol. 2009, 41, 221-227.

23. Hajji-Hedfi, L.; Rebai, E.; Larayedh, A.; Regaieg, H.; Horrigue-Raouani, N. Biological control of Meloidogyne javanica on tomato with Dazitol@and soil solarization. Environ. Sci. Pollut. Res. 2018, 25, 17278-17282. [CrossRef]

24. Zeck, W.M. Rating scheme for field evaluation of root-knot nematode infestations. Pflanzenschutz-Nachr. Bayer 1971, 24, 141-144.

25. Neubauer, C.; Heitmann, B.; Müller, C. Biofumigation potential of Brassicaceae cultivars to Verticillium dahliae. Eur. J. Plant Pathol. 2014, 140, 341-352. [CrossRef]

26. Yim, B.; Hanschen, F.S.; Wrede, A.; Nitt, H.; Schreiner, M.; Smalla, K.; Winkelmann, T. Effects of biofumigation using Brassica juncea and Raphanus sativus in comparison to disinfection using Basamid on apple plant growth and soil microbial communities at three field sites with replant disease. Plant Soil 2016, 406, 389-408. [CrossRef]

27. Morris, E.K.; Fletcher, R.; Veresoglou, S.D. Effective methods of biofumigation: A meta-analysis. Plant Soil 2020, 446, 379-392. [CrossRef]

28. Lazzeri, L.; Tacconi, R.; Palmieri, S. In vitro activity of some glucosinolates and their reaction products toward a population of the nematode Heterodera schachtii. J. Agric. Food Chem. 1993, 41, 825-829. [CrossRef]

29. Pinto, S.; Rosa, E.; Santos, S. Effect of 2-propenyl glucosinolate and derived isothiocyanate on the activity of the nematode Globodera rostochiensis (Woll.). Acta Hortic. 1998, 459, 323-327. [CrossRef]

30. Potter, M.J.; Davies, K.; Rathjen, A.J. Supressive impact of glucosinolates in Brassica vegetative tissues on root lesion nematode, Pratylenchus neglectus. J. Chem. Ecol. 1998, 24, 67-80. [CrossRef]

31. Aissani, N.; Tedeschi, P.; Maietti, A.; Brandolini, V.; Garau, V.L.; Caboni, P. Nematicidal activity of allylisothiocyanate from horseradish (Armoracia rusticana) roots against Meloidogyne incognita. J. Agric. Food Chem. 2013, 61, 4723-4727. [CrossRef]

32. Wood, C.; Kenyon, D.M.; Cooper, J.M. Allyl isothiocyanate shows promise as a naturally produced suppressant of the potato cyst nematode, Globodera pallida, in biofumigation systems. Nematology 2017, 19, 389-402. [CrossRef]

33. Price, A.J.; Charron, C.S.; Saxton, A.M.; Sams, C.E. Allyl isothiocyanate and carbon dioxide produced during degradation of Brassica juncea tissue in different soil conditions. HortScience 2005, 40, 1734-1739. [CrossRef]

34. Borek, V.; Morra, M.J.; Brown, P.D.; McCaffrey, J.P. Transformation of the glucosinolate-derived allelochemicals allyl isothiocyanate and allylnitrile in soil. J. Agric. Food Chem. 1995, 43, 1935-1940. [CrossRef]

35. Dungan, R.S.; Gan, J.; Yates, S.R. Accelerated degradation of methyl isothiocyanate in soil. Water Air Soil Pollut. 2003, 142, 299-310. [CrossRef]

36. Gimsing, A.L.; Poulsen, J.L.; Laurberg, H.; Hansen, H.C.B. Formation and degradation kinetics of the biofumigant benzyl isothiocyanate in soil. Environ. Sci. Technol. 2007, 41, 4271-4276. [CrossRef] [PubMed]

37. Gimsing, A.L.; Strobel, B.W.; Hansen, H.C.B. Degradation and sorption of 2-propenyl and benzyl isothiocyanate in soil. Environ. Toxicol. Chem. 2009, 28, 1178-1184. [CrossRef]

38. Gimsing, A.L.; Kirkegaard, J.A. Glucosinolates and biofumigation: Fate of glucosinolates and their hydrolysis products in soil. Phytochem. Rev. 2009, 8, 299-310. [CrossRef]

39. Hanschen, F.S.; Yim, B.; Winkelmann, T.; Smalla, K.; Schreiner, M. Degradation of biofumigant isothiocyanates and allyl glucosinolate in soil and their effects on the microbial community composition. PLoS ONE 2015, 10, e0132931. [CrossRef]

40. Yu, J.; Vallad, G.E.; Boyd, N.S. Evaluation of allyl isothiocyanate as a soil fumigant for tomato (Lycopersicon esculentum Mill.) production. Plant Dis. 2019, 103, 2764-2770. [CrossRef] 
41. Hanschen, F.S.; Klopsch, R.; Oliviero, T.; Schreiner, M.; Verkerk, R.; Dekker, M. Optimizing isothiocyanate formation during enzymatic glucosinolate breakdown by adjusting $\mathrm{pH}$ value, temperature and dilution in Brassica vegetables and Arabidopsis thaliana. Sci. Rep. 2017, 7, 40807. [CrossRef]

42. Fahed, S.; Abi Antoun, P.; Jawhar, J. Influence of Five Wild Plant Extracts on Nematodes, Meloidogyne sp. Ann. Rech. Sci. 2005, 6, 231-241.

43. Martin, T.J.; Turner, S.J.; Fleming, C.C. Management of the potato cyst nematode (Globodera pallida) with bio-fumigants/stimulants. Commun. Agric. Appl. Biol. Sci. 2007, 72, 671-675.

44. Henderson, D.R.; Riga, E.; Ramirez, R.A.; Wilson, J.; Snyder, W.E. Mustard biofumigation disrupts biological control by Steinernema spp. nematodes in the soil. Biol. Control 2009, 48, 316-322. [CrossRef]

45. Yim, B.; Nitt, H.; Wrede, A.; Jacquiod, S.; Sørensen, S.J.; Winkelmann, T.; Smalla, K. Effects of soil pre-treatment with Basamid@granules, Brassica juncea, Raphanus sativus, and Tagetes patula on bacterial and fungal communities at two apple replant disease sites. Front. Microbiol. 2017, 8, 1604. [CrossRef] [PubMed]

46. Hallmann, J.; Subbotin, S.A. Methods for extraction, processing and detection of plant and soil nematodes. In Plant Parasitic Nematodes in Subtropical and Tropical Agriculture, 3rd ed.; Sikora, R.A., Coyne, D., Hallmann, J., Timper, P., Eds.; CABI: Wallingford, UK, 2018; pp. 87-119.

47. Hallmann, J.; Meressa, B.H. Nematode Parasites of Vegetables. In Plant Parasitic Nematodes in Subtropical and Tropical Agriculture, 3rd ed.; Sikora, R.A., Coyne, D., Hallmann, J., Timper, P., Eds.; CABI: Wallingford, UK, 2018.

(C) 2020 by the authors. Licensee MDPI, Basel, Switzerland. This article is an open access article distributed under the terms and conditions of the Creative Commons Attribution (CC BY) license (http://creativecommons.org/licenses/by/4.0/). 